\title{
KAJIAN EFEKTIVITAS PENGGUNAAN METODE LIT, PIT, DAN QT UNTUK MONITORING TUTUPAN SUBSTRAT
}

\author{
Nur Kholis Wahib ${ }^{\text {a }}$ dan Oktiyas Muzaky Luthfi ${ }^{a^{*}}$ \\ ${ }^{a}$ Ilmu Kelautan, FPIK, Universitas Brawijaya, Jl. Veteran, Kota Malang, Indonesia \\ *Koresponden penulis: omuzakyl@ub.ac.id
}

\begin{abstract}
Abstrak
Penelitian ini bertujuan untuk mengetahui metode yang efektif untuk monitoring tutupan substrat dan untuk mengetahui kondisi substrat di Perairan Pulau Tinabo Besar. Substrat merupakan susunan dasar perairan yang tersusun dari dua komponen, yaitu biotik dan abiotik. Substrat terbagi menjadi dua kategori, yaitu living dan non-living. Pengambilan data dilakukan dengan menggunakan metode Underwater Photo Transect (UPT). Pengolahan data dilakukan dengan menggunakan perangkat lunak ImageJ dan Ms. Excel 2016. Tutupan rata-rata substrat living metode Line Intercept Transect (LIT) sebesar 34\%, tutupan rata-rata substrat living metode Point Intercept Transect (PIT) sebesar 36\%, dan tutupan rata-rata substrat living metode Quadrant Transect (LIT) sebesar 11\%. Perbandingan dari tiga metode untuk monitoring tutupan substrat di Perairan Pulau Tinabo Besar didapatkan hasil monitoring dengan metode Point Intercep Transet (PIT) memiliki nilai living yang lebih besar dari kedua metode lainnya. Metode yang paling efektif untuk monitoring substrat di Perairan Pulau Tinabo Besar adalah metode Point Intercept Transect (PIT) dan kondisi tutupan substrat di Perairan Pulau Tinabo Besar masuk kedalam kategori sedang dengan persentase living sebesar $36 \%$ dan non-living sebesar $64 \%$.
\end{abstract}

Kata Kunci: LIT, PIT, Pulau Tinabo Besar, QT, Substrat

\begin{abstract}
This study aims to find out an effective method for monitoring substrate cover and to determine the condition of the substrate in the Tinabo Besar Island waters. The substrate is a basic arrangement of water which is composed of two components, namely biotic and abiotic. Substrate is divided into two categories, namely living and non-living. Data collection was carried out using the Underwater Photo Transect (UPT) method. Data processing is done using ImageJ and Ms. software. Excel 2016. The average cover of the living substrate for the Line Intercept Transect (LIT) method is 34\%, the average cover of the living substrate of the Point Intercept Transect (PIT) method is 36\%, and the average cover of the living substrate of the Quadrant Transect (PIT) method is $11 \%$. Comparison of the three methods for monitoring substrate cover in Tinabo Besar Island waters obtained by monitoring with the Point Intercep Transet (PIT) method has a greater living value than the other two methods. The most effective method for substrate monitoring in Tinabo Besar Island waters is the Point Intercept Transect (PIT) method and the condition of substrate cover in the Tinabo Besar Island waters is in the medium category with a percentage of living at $36 \%$ and non-living at $64 \%$.
\end{abstract}

Keywords: LIT, PIT, QT, Substrate, Tinabo Besar Island

\section{PENDAHULUAN}

Indonesia merupakan negara maritim dengan luas laut sebesar $70 \%$ dari keseluruhan negara. Indonesia merupakan habitat yang cocok untuk karang tumbuh, dikarenakan Indonesia memiliki iklim tropis. Luas ekosistem terumbu karang yang ada di Indonesia, yaitu sebesar $60.000 \mathrm{~km}^{2}$. Sebaran karang di Indonesia merata dari bagian barat hingga timur Indonesia, namun pertumbuhan karang terbaik berada di perairan Sulawesi,
Maluku, Nusa Tenggara Barat (NTB), Nusa Tenggara Timur (NTT), dan Sorong [1]. Kondisi terumbu karang di Indonesia terbagi menjadi empat kategori, yaitu sangat baik, baik, sedang, dan rusak, sedangkan persentase kondisi terumbu karang di Indonesia 6,39\% dalam kondisi sangat baik, $23,40 \%$ dalm kondisi baik, 35,06\% dalam kondisi sedang, dan 35,15 dalam kondisi rusak [2]

Taman Nasional Taka Bonerate merupakan salah satu kawasan konservasi 
yang berupa Taman Nasional Laut yang ada di Indonesia. Taman Nasional Taka Bonerate memiliki luas kawasan 530.765 ha dan tersusun dari gugusan pulau kecil yang terletak di Laut Flores [3]. Secara administratif kawasan Taman Nasional Taka Bonerate terdapat enam desa, yaitu Desa Rajuni, Desa Latondu, Desa Tarupa, Desa Jinato, Desa Tambuna, dan Desa Pasitallu Raya [4]. Taman Nasional Taka Bonerate ditetapakan sebagai kawasan pelestarian alam yang merupakan atol terbesar ketiga didunia (luasan 220.000 ha) setelah Atol Kwajifein di Kepulauan Marshal dan Atol Sulvadiva di Maladewa [5]. Kondisi substrat di Taman Nasional Taka Bonerate didominasi alga dengan persentase 39\% dan karang 32\% [6].

Substrat merupakan susunan dasar perairan yang disusun oleh dua komponen utama, yaitu komponen biotik dan abiotik [7]. Substrat dasar perairan dibagi menjadi dua kategori, yaitu living dan non-living. Living merupakan substrat yang tersusun dari komponen biotik, contoh dari substrat kategori living, yaitu karang keras, karang lunak, dan alga. Non-living merupakan substrat yang tersusun dari komponen abiotik, contoh dari substrat kategori non-living, yaitu pasir, lumpur, dan pecahan karang [8]. Terumbu karang suatu ekosistem yang berada didasar laut dan penyusun utamanya adalah karang keras (scleractinian) [1]. Terumbu karang memiliki peranan penting yang dapat dinilai dari dua aspek, yaitu aspek ekologis dan aspek ekonomis. Peran ekologis terumbu karang diantaranya, sebagai tempat mencari makan, tempat tinggal, dan tempat berkembang biak biota lain. Peran ekonomis terumbu karang, yaitu sebagai objek wisata karena memiliki keindahan dan memuat banyak biota [9].

Pengamatan kondisi substrat dapat dilakukan dengan berbagai macam metode, diantaranya metode Line Intercept Transect (LIT), Point Intercept Transect (PIT), dan Quadrant Transect (QT). Line Intercept Transect (LIT) merupakan metode yang digunakan dalam survei terumbu karang. Metode LIT dikembangkan oleh Australian
Institute of Marine Science (AIMS) dan The Great Barrier Reef Marine Park Authority (GBRMPA) [10]. Point Intercept Transect (PIT) merupakan metode yang digunakan untuk melakukan survei terumbu karang. Metode PIT digunakan untuk memperkirakan kondisi terumbu karang disuatu lokasi berdasarkan persen tutupan karang hidup [11]. Quadran Transect (QT) merupakan metode yang digunakan untuk memantau komunitas makrobentos. Pada survei terumbu karang dengan menggunakan metode QT biasanya meliputi kondisi biologi, pertumbuhan, tingkat kematian, dan rekruitmen karang baru [12].

Perairan Pulau Tinabo Besar merupakan salah satu Pulau yang terletak didalam kawasan Taman Nasional Taka Bonerate. Secara geografis Pulau Tinabo Besar terletak diantara $-6.56134^{0} \mathrm{LS}-121.1021^{0}$ BT [6]. Kondisi tutupan karang di Perairan Pulau Tinabo masuk kedalam kategori rusak hingga sedang $(11,87-38,80 \%)$, dengan persentase rata-rata $25,3 \%$ yang termasuk kedalam kategori sedang [13]. Metode yang digunakan dalam penelitian ini adalah underwater photo. Tujuan dari penelitian ini adalah untuk mengetahui metode yang efektiv untuk monitoring kondisi substrat dan mengetahui kondisi substrat di Perairan Pulau Tinabo Besar Taman Nasional Taka Bonerate.

\section{BAHAN DAN METODE}

\section{Waktu dan Tempat}

Pengambilan data penelitian dilakukan pada 23-24 Juli 2018 di Perairan Pulau Tinabo Besar, Taman Nasional Taka Bonerate, Kabupaten Kep. Selayar, Sulawesi Selatan. Pengambilan data dilakukan diempat stasiun, stasiun 1 berada dibagian selatan pulau ($\left.6.580725^{0} \mathrm{LS}-121.097203^{0} \mathrm{BT}\right)$, stasiun 2 berada dibagian timur pulau $\left(-6.569031^{\circ} \mathrm{LS}-\right.$ $121.108492^{0} \mathrm{BT}$ ), stasiun 3 berada dibagian utara pulau $\left(-6.561089^{\circ}\right.$ LS - $121.101719^{\circ}$ BT), dan stasiun 4 berada dibagian barat pulau $\left(-6.565300^{\circ}\right.$ LS - $121.097211^{0}$ BT). Titik pengambilan data secara lebih jelas dapat dilihat pada (Gambar 1). 


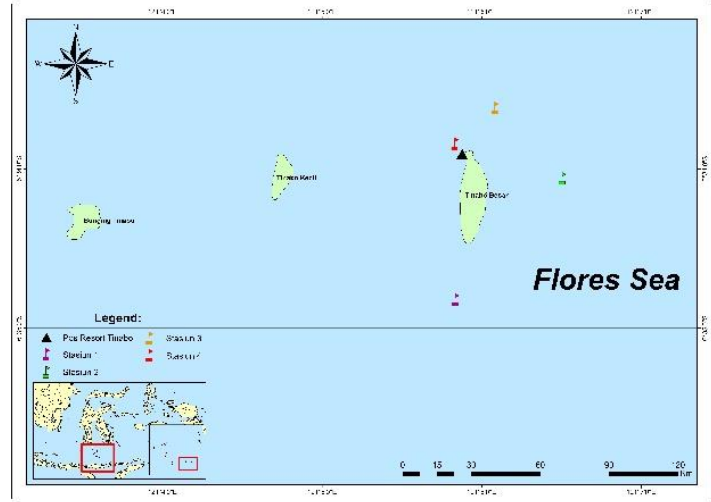

Gambar 1. Peta Lokasi Penelitian

\section{Pengambilan Data}

Alat dan bahan yang digunakan dalam penelitian ini adalah perahu motor, SCUBA set, rollmeter, frame, kamera underwater, laptop, perangkat lunak ImageJ, dan perangkat lunak Ms. Excel 2016. Pengambilan data kondisi substrat dilakukan pada kedalaman 4 - 6 meter. Pengambilan data dilakukan dengan menggunakan Underwater Photo Transect (UPT). Panjang transek yang digunakan, yaitu 50 meter dengan ukuran frame $1 \mathrm{~m} \times 1 \mathrm{~m}$. Pengambilan data dilakukan disetiap meternya, sehingga didapatkan 50 data.

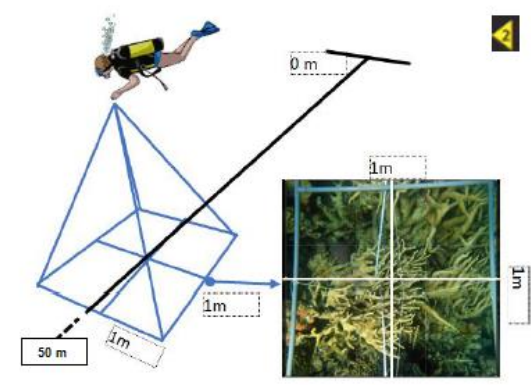

Gambar 2. Metode UPT

\section{Pengolahan Data}

Pengolahan data Line Intercept Transect (LIT) dan Point Intercept Transect (PIT) dilakukan dengan menggunakan perangkat lunak Ms. Excel 2016. Persentase tutupan substrat dengan metode Line Intercept Transect (LIT) dapat dihitung dengan rumus sebagai berikut [14]:

$$
\mathrm{C}=\frac{\mathrm{a}}{\mathrm{A}}
$$

Keterangan:

C : Persentase lifeform i

a : Panjang total lifeform i

A : Panjang transek

Persentase tutupan substrat dengan metode Point Intercept Transect (PIT) dapat dihitung dengan rumus sebagai berikut [8]:

$$
\mathrm{C}=\frac{\Sigma(\mathrm{i})}{\mathrm{A}} \times 100 \%
$$

Keterangan:

C : Tutupan Karang

$\Sigma(i)$ : Jumlah titik setiap tipe substrat

A : Jumlah total kisi yang digunakan dalam pengambilan data (80 titik)

Pengolahan data Quadrant Transect (QT) dilakukan dengan perangkat lunak ImageJ untuk mengetahui luasan substrat living. Data luasan yang telah didapat kemudian diolah dengan meggunkan perangkat lunak Ms. Excel 2016 untuk mendapatkan persentase substrat. Persentase tutupan substrat dengan metode Quadrant Transect (QT) dapat dihitung dengan rumus sebagai berikut [15]:

$$
\mathrm{P}=\frac{\mathrm{L}}{\mathrm{A}}
$$

Keterangan:

$\mathrm{P} \quad$ : Persentase substrat living

L : Luas substrat living $\left(\mathrm{cm}^{2}\right)$

A : Luas Transek $\left(\mathrm{cm}^{2}\right)$

Penilaian untuk mengetahui kondisi substrat menggunakan penilaian sebagai berikut [2]:

1. Rusak $(0-25 \%)$

2. Sedang $(26-50 \%)$

3. Baik $(51-75 \%)$

4. Sangat baik $(76-100 \%)$ 


\section{HASIL DAN PEMBAHASAN}

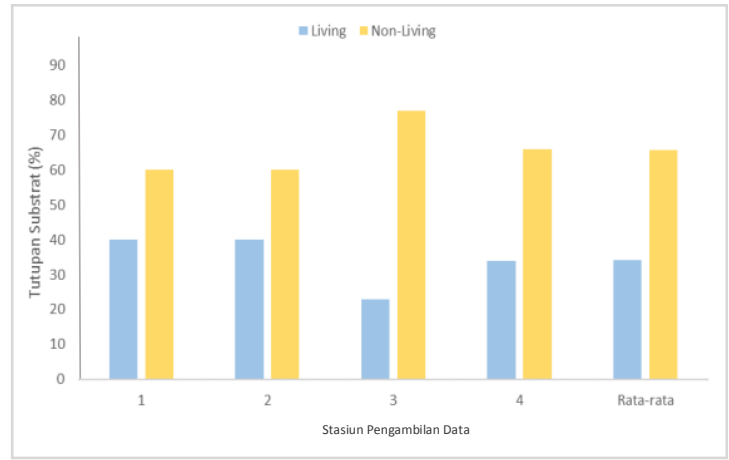

Gambar 3. Persentase Tutupan Substrat dengan Metode LIT

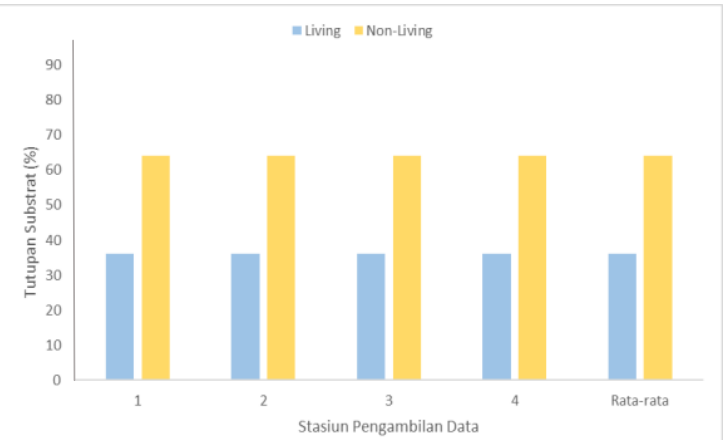

Gambar 4. Persentase Tutupan Substrat dengan Metode PIT

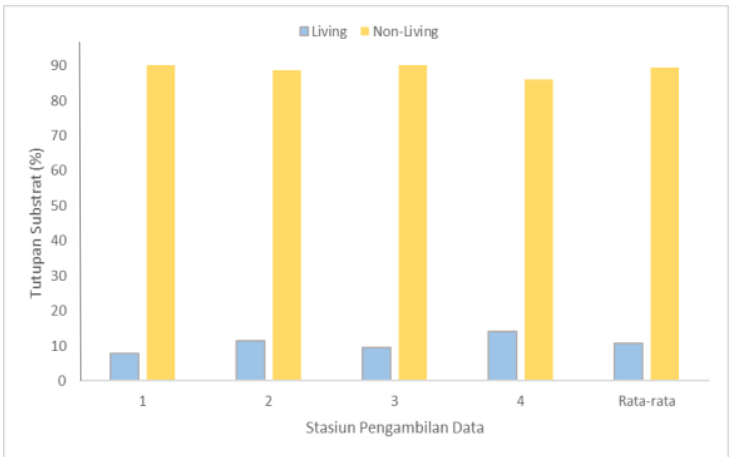

Gambar 5. Persentase Tutupan Substrat dengan Metode QT

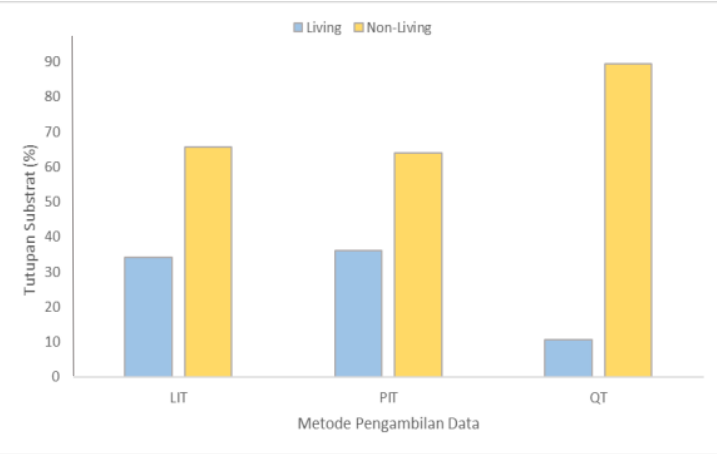

Gambar 6. Persentase Rata-Rata Tutupan Substrat dengan Ketiga Metode

\section{Tutupan Substrat dengan Metode LIT}

Persentase tutupan substrat dengan metode Line Intercept Transect (LIT) di stasiun 1 dan 2 didapatkan hasil living 40\% dan non-living $60 \%$. Persentase tutupan substrat dengan metode Line Intercept Transect (LIT) di stasiun 3 didapatkan hasil living $23 \%$ dan non-living $77 \%$. Persentase tutupan substrat dengan metode Line Intercept Transect (LIT) di stasiun 4 didapatkan hasil living $34 \%$ dan non-living $66 \%$. Persentase tutupan substrat rata-rata dengan metode Line Intercept Transect (LIT) didapatkan hasil living $34 \%$ dan non-living $66 \%$. Persentase tutupan substrat dengan metode LIT secara lebih jelas dapat dilihat pada (Gambar 3). Persantase tutupan substrat terbagi menjadi empat kategori, yaitu rusak $(0 \%$ - $25 \%)$, sedang (26\% - 50\%), Baik (51\% - 75\%), dan sangat baik (76\% - 100\%) [2]. Persentase ratarata tutupan substrat dengan metode Line Intercept Transect (LIT) di Perairan Pulau Tinabo Besar termasuk kedalam kategori sedang dengan persentase rata-rata living sebesar $34 \%$.

\section{Tutupan Substrat dengan Metode PIT}

Persentase tutupan substrat yang didapat dengan metode Point Intercept Transect (PIT) di empat stasiun Perairan Pulau Tinabo Besar didapatkan hasil yang sama. Hasil dari metode point Intercept Transect (PIT), yaitu living $36 \%$ dan non-living 64\%. Rata-rata tutupan substrat dengan meode Point Intercept Transect (PIT), yaitu living 36\% dan non- 
living 64\%. Persentase tutupan substrat dengan metode PIT secara lebih jelas dapat dilihat pada (Gambar 4). Persantase tutupan substrat terbagi menjadi empat kategori, yaitu rusak $(0 \%-25 \%)$, sedang $(26 \%-50 \%)$, Baik $(51 \%-75 \%)$, dan sangat baik $(76 \%-100 \%)$ [2].Persentase rata-rata tutupan substrat dengan metode Point Intercept Transect (PIT) di Perairan Pulau Tinabo Besar termasuk kedalam kategori sedang dengan persentase rata-rata living sebesar $36 \%$.

\section{Tutupan Substrat dengan Metode QT}

Persentase tutupan substrat dengan metode Quadrant Transect (QT) yang didapatkan di stasiun 1 Perairan Pulau Tinabo Besar living $8 \%$ dan non-living $92 \%$. Persentase tutupan substrat dengan metode Quadrant Transect (QT) yang didapatkan di stasiun 2 Perairan Pulau Tinabo Besar living $11 \%$ dan non-living $89 \%$. Persentase tutupan substrat dengan metode Quadrant Transect (QT) yang didapatkan di stasiun 3 Perairan Pulau Tinabo Besar living 10\% dan non-living $90 \%$. Persentase tutupan substrat dengan metode Quadrant Transect (QT) yang didapatkan di stasiun 4 Perairan Pulau Tinabo Besar living 14\% dan non-living $86 \%$. Ratarata tutupan substrat dengan meode Quadrant Transect (QT), yaitu living $11 \%$ dan nonliving $89 \%$. Persentase tutupan substrat dengan metode QT secara lebih jelas dapat dilihat pada (Gambar 5). Persantase tutupan substrat terbagi menjadi empat kategori, yaitu rusak $(0 \%-25 \%)$, sedang $(26 \%-50 \%)$, Baik $(51 \%-75 \%)$, dan sangat baik $(76 \%-100 \%)$ [2]. Persentase rata-rata tutupan substrat dengan metode Point Intercept Transect (PIT) di Perairan Pulau Tinabo Besar termasuk kedalam kategori rusak dengan persentase rata-rata living sebesar $11 \%$.

\section{Perbandingan Tiga Metode}

Persentase rata-rata tutupan substrat dengan metode Line Intercept Transect (LIT) di Perairan Pulau Tinabo Besar living 34\% dan non-living $66 \%$. Persentase rata-rata tutupan substrat dengan metode Point Intercept Transect (PIT) di Perairan Pulau Tinabo Besar living 36\% dan non-living 64\%. Persentase rata-rata tutupan substrat dengan metode Quadrant Transect (QT) di Perairan Pulau Tinabo Besar living $11 \%$ dan non-living $89 \%$. Persentase living terbesar didapatkan dengan metode PIT, sedangkan persentase living terkecil didapatkan dengan metode QT. Persentase rata-rata tutupan substrat dengan metode LIT, PIT, dan QT dapat dilihat lebih jelas pada (Gambar 6). Penggunaan metode untuk monitoring tutupan substrat di Perairan Pulau Tinabo Besar, Taman Nasional Taka Bonerate adalah Point Intercept Transect (PIT), karena memiliki persentase living terbesar.

\section{KESIMPULAN DAN SARAN}

\section{Kesimpulan}

Metode yang paling efektif digunakan untuk monitoring substrat di Perairan Pulau Tinabo Besar, Taman Nasional Taka Bonerate adalah Point Intercept Transect (PIT), dikarenakan metode PIT memiliki persentase living yang lebih besar dari metode LIT dan QT. Kondisi substrat di Perairan Pulau Tinabo Besar, Taman Nasional Taka Bonerate yang dihitung dengan metode Point Intercept Transect (PIT) termasuk kategori sedang dengan persentase living sebesar $36 \%$ dan non-living sebesar $64 \%$.

\section{Saran}

Saran yang dapat diberikan dari hasil penelitian ini, yaitu pada proses pengambilan data sebaiknya dilakukan saat cuaca teduh dan arusnya tidak kuat agar foto yang dihasilkan memiliki kualitas yang baik. Kualitas foto yang baik sangat membantu dalam proses pengidentifikasian.

\section{UCAPAN TERIMA KASIH}

Terima kasih penulis ucapkan kepada kepala Balai Taman Nasional Taka Bonerate Faat Rudhianto, S. Hut., M. Si serta jajaran stafnya yang telah memberikan izin, bantuan, dukungan, serta sarana guna berlangsungnya penelitian ini. Terima kasih penulis juga sampaikan kepada teman-teman serta pembimbing lapang Praktik Kerja Magang (PKM) penulis yang telah membantu dalam proses pengambilan data. 


\section{DAFTAR PUSTAKA}

[1] Suharsono, "Jenis-Jenis Karang di Indonesia," LIPI-Press, 2008.

[2] Giyanto, M. Abrar, T. A. Hadi, A. Budiyanto, M. Hafizt, A. Salatalohy, dan M. Y. Iswari, "Status Terumbu Karang Indonesia 2017," Puslit Oseanografi-LIPI, Jun 2017.

[3] A. R. HB, I. N. Dewi, dan N. Hayati, "Etnoekologi Masyarakat Sekitar Taman Nasional Taka Bonerate dalam Pemanfaatan Kima Lubang (Tridacna Crocea) dan Ikan Malaja (Siganus canaliculatus)," Jurnal Penelitian Kehutanan Wallace, vol. 3, no. 2, hal. 139-149, Jun 2014.

[4] TNTBR.

"Sejarah". http://tntakabonerate.com/id/sejarah-2/, Sep 2018.

[5] W. P. Lestari, E. Muttaqin, Sahabudin, S. A. Amar, S. F. Dzat, dan Ibrahim. "Laporan Survei Sosial Ekonomi Taman Nasional Taka Bonerate 2015," Wildlife Conservation Society. Sep 2015.

[6] S. Pardede, S. A. R. Tarigan, F. Setiawan, Muhidin, A. M. Yasir, dan E. Muttaqin, "Status Ekosistem Terumbu Karang Taman Nasional Taka Bonerate, 2015," Wildlife Conservation Society, Sep 2015.

[7] R. W. Ariyati, L. Sya'rani, dan E. Arini, "Analisis Kesesuaian Perairan Pulau Karimunjawa Dan Pulau Kemujan Sebagai Lahan Budidaya Rumput Laut Menggunakan Sistem Informasi Geografis," Jurnal Pasir Laut, vol. 3 no. 1, hal. 27-45, Jul 2007.

[8] G. Hodgson, J. Hill, W. Kiene, L. Maun, J. Mihaly, J. Liebeler, C. Shuman, dan R. Torres, "Instruction Manual: A Guide to Reef Check Coral
Reef Monitoring," Reef Check Foundation, 2006.

[9] H. Suryanto, F. Yulianda, dan Y. Wardiatno, "Analisis Status Terumbu Karang Untuk Pengembangan Wisata Bahari Di Desa Teluk Buton Kabupaten Natuna," Jurnal Ilmu-Ilmu Perairan dan Perikanan Indonesia, vol. 16, no. 2, hal. 137-143, Des 2009.

[10] Y. Dhahiyat, D. Sinuhaji, dan H. Hamdani, "Struktur Komunitas Ikan Karang Di Daerah Transplantasi Karang Pulau Pari, Kepulauan Seribu," Jurnal Iktiologi Indonesia, vol. 3, no. 2, hal. 87-94, Des 2003.

[11] Z. Afandy, dan E. A. Supeni, "Kondisi Terumbu Karang Di Pesisir Barat Pulau Kei Kecil, Kabupaten Maluku Tenggara," Jurnal Neritic, vol. 5 no. 1 hal. 8-14, Mar 2014.

[12] J. Ofri, "Sistematis dan Teknik Identifikasi Karang: Traning Course Karakteristik Biologi Karang," PS-UI dan Yayasan TERANGI, Mei 2003.

[13] M. A. Ghiffari, A. Irham, S. A. Harahap, N. Kurniawaty, dan S. Astuty, "Hubungan Kondisi Terumbu Karang Dengan Kelimpahan Ikan Karang Target Di Perairan Pulau Tinabo Besar, Taman Nasional Taka Bonerate, Sulawesi Selatan," Jurnal Spermonde, vol. 2 no. 3 hal. 17-24, Apr 2017.

[14] S. English, C. Wilkinson, dan V. Baker, "Survey Manual for Tropical Marine Resources," Australian Institute of Marine Science, 1997.

[15] J. Hill, dan C. Wilkinson, "Methods for Ecological Monitoring of Coral Reefs," Australian Institute of Marine Science, 2004. 